East African Medical Journal Vol. 86 No. 2 February 2009

ENCEPHALOCELE - A SINGLE INSTITUTION AFRICAN EXPERIENCE

N. Munyi, Surgical Resident, AIC Kijabe Hospital, D. Poenaru, MD, MHPE, FACS, FCS (ECSA), Adjust Professor of Surgery, Queen's University, Kingston Canada, Medical Director,Bethanykids, Kijabe Hospital, P.O. Box 20-00220, Kijabe, Kenya, R. Bransford, and L. Albright, MD, FACS, Professor of Surgery, University of Wisconsin, School of Medicine

Request for reprints to: Prof. D. Poenaru, P.O. Box 20- 00220, Kijabe, Kenya

\title{
ENCEPHALOCELE - A SINGLE INSTITUTION AFRICAN EXPERIENCE
}

\author{
N. MUNYI, D. POENARU, R. BRANSFORD and L. ALBRIGHT
}

\begin{abstract}
Objective: This study seeks to find out the presentation, management and complications of encephaloceles in an African setting.

Design: a retrospective study reviewing the age and sex of the patients, type and contents of encephaloceles, associated anomalies, preoperative evaluation and investigations, surgical approaches, intra- and post-operative complications as well as follow-up outcomes.

Setting: Bethany Crippled Children's centre and Bethanykids at Kijabe Hospital (BKKH), between January 1998 and August 2006.

Patients: Of the 53 patients seen, 23 were males and 30 females. The median age at presentation was four months.

Results: The follow-up period extended to eight years. Twenty nine patients had occipital encephaloceles, and 39 were operated using the direct external approach. Cererobrospinal fluid leak was the most common post-operative complication. Recurrence occurred in four patients and death in six.

Conclusions: Most of the encephalocele patients managed at BKKH had good outcomes and proceeded to live normal or near-normal lives. Our study confirms that even in resource-constrained areas, children with encephaloceles can be successfully managed with acceptable outcomes.
\end{abstract}

\section{INTRODUCTION}

Encephaloceles are rare congenital lesions consisting of a herniation of intracranial contents from the cranial cavity. They may consist of meninges alone (meningoceles), may contain brain tissue (meningoencephalocele or encephalocele) and may include a ventricle (hydroencephalocele ningocele) (1).

Questions have been raised as to whether encephaloceles are truly neural tube defects (NTDs). According to Humphreys (1), only some are NTDs. Rowland etal (2)found that with folic acid fortification, prevalence decreased for spina bifida but not significantly for encephalocele or anencephaly.

The incidence of encephaloceles varies with geographical location and race (3), with the overall incidence being 0.8 - 3.0 per 10,000 live births (4-7). Occipital encephaloceles are the most common typein NorthAmericaand Western Europe, with an incidence of $0.3-1$ per 10,000 live births. They comprise $85 \%$ of all encephaloceles (8-10). Seventy per cent of occipitalencephaloceles are in females, and $15-20 \%$ are associated with other NTDs. Anterior encephaloceles are the most common type in South-East Asia, Russia and Central Africa - with an incidence of 1:3,500 to 1:5,000 (11).
Encephaloceles are classified into several types according to the anatomical location of the skull defect (3): convexity (occipital, parietal, saggital, occipital-cervical), sincipital (frontoethmoidal, nasofrontal, nasoethmoidal, naso-orbital, interfrontal, craniofacial cleft), basal (intranasal, spheno-orbital, sphenomaxillary, spenopharyngeal), and atretic.

Though encephaloceles are rare congenital malformations, they are associated with severe morbidity and mortality if untreated. However, most reported series of encephaloceles originate in developed nations, where resources for their treatment are radically different than in Africa. This study seeks to find out the presentation, management and complications of encephaloceles in an African setting as well as answer the question: "Canencephaloceles be successfully managed in a resource-poor setting?"

\section{MATERIALS AND METHODS}

This was a retrospective study of patients presenting with encephaloceles at two sister institutions in Kijabe, Kenya (Bethany Crippled Children's Centre and BethanyKids at Kijabe Hospital) over a period of eight years (January 1998 to August 2006). Both hospital charts and electronic records were used to retrieve the data. 
Of the 60 patients diagnosed with encephaloceles during the study period, seven had missing records and were therefore not included in the study.

The study reviewed the age and sex of patients, type and contents of the skull defect, associated anomalies, preoperative evaluation and investigations, surgical approaches, intra- and post-operative complications as well as follow-up outcomes. Statistical analysis performed in SPSS ${ }^{\circledast}$ included descriptive and correlative statistics, using a p-value of 0.05 .

The study was approved by the Ethics Committee of AIC Kijabe Hospital. All patients data were separated from names or any other identifiers, and records were kept securely to ensure full anonymity and confidentiality.

\section{RESULTS}

During the study period there were 53 patients: 23 males and 30 females. Themean age at first presentation varied from one day to 15 years, with a mean of 24 months and standard deviation of 45 months.

The defect types are presented in Table 1. Within the convexity type 29/33(88\%) were occipital encephaloceles (Figure 1). These constituted about $55 \%$ of all encephaloceles.

Table 1

Types of encephaloceles

\begin{tabular}{lcc}
\hline Type & No. & $(\%)$ \\
\hline Convexity & 33 & 62 \\
Sincipital & 19 & 36 \\
Basal & 0 & 0 \\
Complex & 0 & 0 \\
Unclassified & 1 & 2 \\
\hline
\end{tabular}

Figure 1A

Giant occipital encephalocele pre-operatively. In view of the associated microcephaly, the prognosis was deemed poor and the resection was only performed to ease care of the child and increase social acceptance within the community

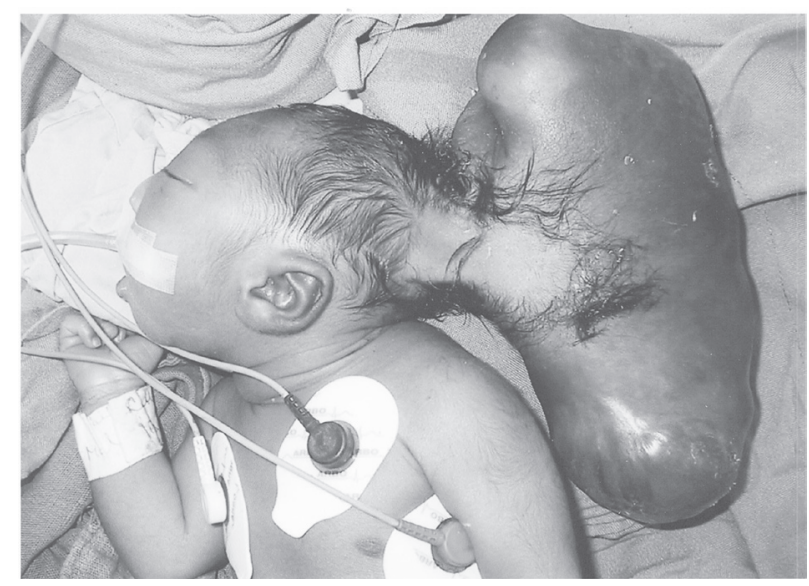

\section{Figure 1B}

Same child as in Figure 1A, six months post-operatively. The child feeds well, responds appropriately, but suffers from gastro-oesophageal reflux

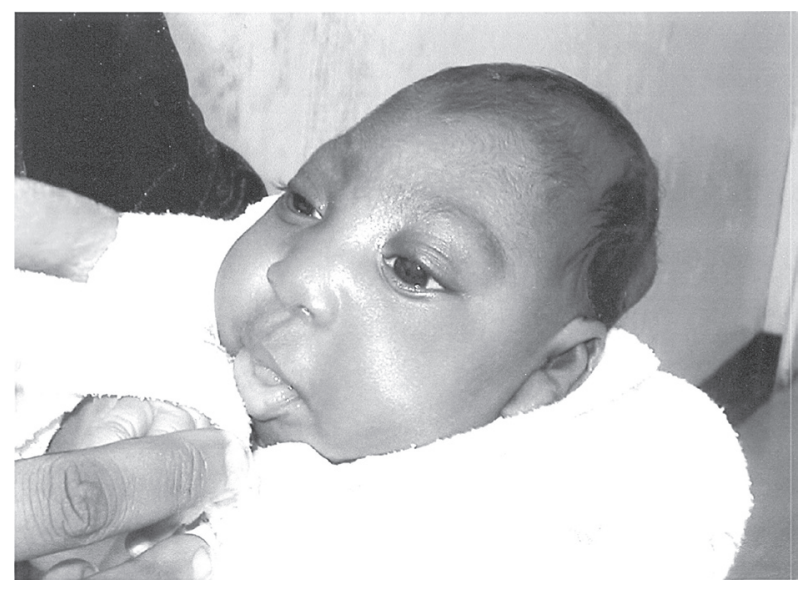

Hydrocephalus was the most common associated anomaly, occurring in $19(36 \%)$ patients. Other associated anomalies occurred in $28(53 \%)$ patients, including microcephaly, rocker bottom foot, posterior fossa cyst, lymphangiomatosis, imperforate anus, paraplegia, mental retardation, subdural hygroma, convulsions and craniosynostosis. There was no statistically significant differencebetween sincipital and occipital typesin terms of sex distribution, associated anomalies, intra- and postoperative complications and status at the last follow-up visit. Imaging studies were limited to ultrasound in $30 / 53(56.6 \%)$, with only $12(22.6 \%)$ patients having computed tomography (CT) scans.

Preoperative preparation included a complete blood count or a haemoglobin level. No pre-operative medication was routinely given other than antibiotic prophylaxis in the form of cephalexin or combined cloxacillin with gentamycin.

Forty nine (92\%) patients underwent the encephalocele repair, using one of several approaches. The direct external approach was the most common, used in $39(80 \%)$ cases. Eight $(16 \%)$ patients had an intracranial approach while two $(4 \%)$ underwent a combined anterior and medial approach. This latter approach was used on two patients with sincipital encephaloceles and hypertelorism, with excellent results. The intracranial approach was used on seven patients with frontoethmoidal encephaloceles and one interfrontal defect. All occipital encephaloceles were operated on using the direct external approach. Titanium mesh reconstruction of the skull defect was used in only a handful of cases. The four children not operated on included one deemed inoperable due to multiple congenital defects and sent home for palliative care, another whose surgery was delayed because of infection, one who had been operated elsewhere, and one who died within two days of insertion of a ventriculo-peritoneal shunt (VPS). 
The encephalocele sac contents were varied. Sixteen (33\%) contained brain tissue, from minimal amount to virtually the entire brain. Four $(8 \%)$ had other contents including scar tissue, fibrous tissue and fat. Twenty nine $(59 \%)$ contained CSF only.

Intra-operative complications occurred in six patients $(12 \%)$. These included mostly problems with dural closure. Defect closure was aborted in two cases due to cardiac arrest in one and brainstem involvement in the other. Other intra-operative complications included dislodgment of a bone graft and accidental extubation.

Twenty six $(49 \%)$ patients required additional surgery, the majority 17 / 26(65\%) being VPSinsertions. Other surgeries included craniotomies, cranioplasties, secondary closure and incision and drainage of an abscess. Twenty children had early post-operative complications, with CSF leak being the most common one, occurring in six $(12 \%)$ patients. Other early complications included fever (two cases), wound skin dehiscence (one cases), wound infection (one cases), facial/ forehead edema (two cases), skin necrosis (one cases), bleeding (one case) and seizures (two cases). There were two early post-operative deaths, both occurring in neonates with occipital encephaloceles. One was a sudden cardiac arrest with no obvious cause; the other neonate had a giant encephalocele with virtual intracranial anencephaly. Table 2 includes the complete operative mortality report.

Late post-operative complications occurred in $12(24 \%)$ patients. These included four deaths, three recurrences, and one brain abscess. Hydrocephalus was eventually diagnosed and treated in 19 patients $(36 \%)$. Eight $(15 \%)$ patients had signs of significant neurodevelopmental delay / cerebral palsy.

The average follow-up length was 10.4 months with a range of 0-110 months. Of those followed up, $30(56.6 \%)$ were reported to be doing well with no mental, physical or neurological defect.

\section{DISCUSION}

Encephaloceles are rare neurosurgical conditions that often present significant challenges in management. Our study includes 53 cases of encephalocele over a period of eight years which constitutes one of the largest series in the literature. Unfortunately, population-based data are not readily available and therefore no conclusions can be made on the true incidence of this condition.

In our study there were slightly more females than males, with a male: female ratio of 1:1.4. The female preponderance was even more distinct in occipital encephaloceles where the M: F ratio was 1:1.6. This is in keeping with the literature which reports that $70 \%$ of occipital encephaloceles occur in females (1). In Nigeria this ratio was found to be 1:2 (8). There was however no significant difference in the sex distribution between the sincipital and convexity groups - in fact we did not find any statistically significant difference in any of the parameters. This might partly be due to our limited sample size.

In our series occipital encephaloceles were the most common type, contributing to $53 \%$ of all encephaloceles. The anterior or sincipital group contributed only $33 \%$ overall. This is in keeping with Nigerian studies with $69 \%$ of lesions in the occipital region $(12,13)$ though Asian and central African studies have found a lower relative incidence of occipital defects (14). No basal encephaloceles were encountered during the study period. This could partly be due to our limited capacity to detect them, as magnetic resonance imaging (MRI) is necessary for their visualisation (11).

Our patients presented at a median age of 2.8 months earlier than in the Asian study (14) but not as early as in Nigeria - where the majority of patients presented before one month of age (12).

Table 2

Mortality report

\begin{tabular}{|c|c|c|c|c|c|c|}
\hline Sex & Age & Location & Surgical approach & Complication & $\begin{array}{l}\text { Follow-up } \\
\text { length }\end{array}$ & Cause of death \\
\hline $\mathrm{M}$ & 2.9 years & Parietal & Direct external approach & None & 12 days & Unknown \\
\hline M & 1 month & Occipital & Direct external approach & Sepsis & 11 months & Unknown \\
\hline $\mathrm{F}$ & 9 months & Occipital & Direct external approach & Shunt malfunction & 1 month & $\begin{array}{l}\text { Unknown; } \\
\text { Elevated ICP }\end{array}$ \\
\hline M & 12 days & Occipital & Direct external approach & & None & Severe microcephaly \\
\hline $\mathrm{F}$ & 15 days & Occipital & Direct external approach & Death & None & $\begin{array}{l}\text { Sudden cardiac } \\
\text { arrest } 2 \text { hours } \\
\text { post-operatively }\end{array}$ \\
\hline M & 17 months & Frontoethmoidal & Direct external approach & \multicolumn{3}{|c|}{$\begin{array}{l}\text { HIV +ve, Kwashiorkor, } \\
\text { Post-operative: blind, cerebral } \\
\text { palsy }\end{array}$} \\
\hline
\end{tabular}


According totheliterature, repairofencephaloceles without ongoing CSF leak is an elective procedure. It should however be done as early as possible for all defects, depending on the anesthesia expertise available (11). Shokunbi and others from Nigeria report that a third of the lesions were excised within one week of presentation and $52(91 \%)$ patients were treated in infancy (8). Most of our cases were operated upon presentation. Therewereseveral reasonsfor this. Patients sent home without intervention are likely to be lost to follow-up. Also the child with a large encephalocele is socially unacceptable to the community and viewed as "cursed" - sending such a child home therefore becomes a "death sentence". Moreover, our local anaesthesia support is quite good for neonates.

The occurrence of hydrocephalus in $36 \%$ of our cases was similar to the rates found by Mealey and Dzenitis (15), and well within the range in the literature $(16 \%$ (8), $50 \%$ (9), and $65 \%(10)$. There was however no hydrocephalus reported in the nasofrontal group (11).

Several clinical and paraclinical methods can be used in the assessment of encephaloceles. Clinically one can determine the location and size of the lesion externally. Transillumination of the sachelps disclose how much cerebral tissue is present as opposed to CSF. Ultrasound gives a more accurate picture of the content of the sac and the ventricular size. CT is used to assess the brain and bony anatomy. Due to their social status, most of our patients were unable to access imaging modalities. CT scan was therefore reserved for complexnasofrontal lesions, with clinical diagnosis alone being used in the other patients.

While the use of spinal drains and / or fibrin glue has been elsewhere found to significantly reduce the risk of CSF leak (11), our resources did not allow for this.

The contents of the dural sac can be extremely variable - in Simpson's series, 32\% had recognisable cortex, $11 \%$ had cerebellum and fourth ventricular structures, and $12 \%$ had glial tissue (16). As expected, the prognosis is inversely related to the amount of neural tissue found in the sac and the severity of associated anomalies. In keeping with this, our series of patients had a good prognosis ( $89 \%$ survival rate) and the majority of children developed normally. This long-term outcome compares favourably with the Asian series, in which $53 \%$ of patients grew up physically and mentally normal, $28 \%$ had normal intelligence but physical impairment, and $19 \%$ had mental retardation (7).

Surgical recurrence rate was low in our group (6\%). It did not appear related to the type of encephaloceles and occurred predominantly early, within four months of surgery.

The management of encephaloceles in the African setting is challenging, but feasible. Our series supports an aggressive surgical attitude, which can lead to acceptable short- and medium-term results. Further studies are needed to establish the long-term outcome of African children with this condition.

\section{ACKNOWLEDGEMENT}

We acknowledge the assistance of AIC KijabeHospital in obtaining the records of the patients.

\section{REFERENCES}

1. Jeffrey,V., Rosenfeld and D.A.K. Watters. Neurosurgery in the tropics: A practical approach to common problems, Macmillan Education Ltd, 2000.

2. Courtney, A., Rowland, M.D., Adolfo, Correa, M.D., et al. Are encephaloceles neural tube defects? Pediatrics. 2006; 118: 916-923.

3. Suwanwela, C. and Suwanwela, N. A morphological classification of sincipital encephalomeningoceles. J. Neurosurg. 1972; 36: 201-211.

4. Macfarlane, R., Rutka, J.T., Armstrong, D. et al. Encephaloceles of the anterior cranial fossa. Pediatric Neurosurg. 1995; 23: 148-158.

5. Simpson, D.A., David, D.J. and White, J. Cephaloceles treatment, outcome, and antenatal diagnosis. Neurosurg. 1984; 15:15-21.

6. Richards, C.G.M. Frontoethmoidal meningoencephalocele: A common and severe congenital abnormality in South East Asia. Arch. Dis. Child. 1992; 67: 717-719.

7. French, B.N. Midline fusion defects and defects of formation. In: Youmans JR, ed. Neurosurgical Surgery. Philadelphia, PA: WB Saunders Co; 1990: 1160-1165.

8. Shokunbi, T., Adeloye, A. and Olumid, A. Occipital encephaloceles in 57 Nigerian children: a retrospective analysis. Child's Nervous System 1990; 6:99-102.

9. Chapman, P.H., Swearingen, B. and Caviness, V.S. Subtorcular occipital encephaloceles. J. Neurosurg. 1989; 71: 375-381.

10. Lorber, J. and Schonfield, J.K. The prognosis of occipital encephalocele. Z Kinderchir. 1979; 28: 347351.

11. Principles and Practice of Pediatric Neurosurgery by L. Albright, I.Pollack and D. Adelson New York Chap 10 pg 189-208, 1999.

12. V.A. Adetiloye, F.O. Dare and O.A. Oyelami A tenyear review of encephalocele in a teaching hospital. Inter. J. Gynecol. Obstetr. 1993; 41: 241-249.

13. O.A. Mabogunje, Cranium bifidum in northern Nigeria Child's Nervous System, 1990; 6: 95-98.

14. Agthong, S. and Wiwanitkit, V., Encephalomeningocele cases over 10 years in Thailand, a case series, BMC Neurology. 2002; 14: 2-3.

15. Mealey, Jr J. and Dzenitis, A.J. The prognosis of encephaloceles. J. Neurosurg. 1970; 32: 209-218.

16 Nadich, T.P., Altman, N.R., Brafman, B.H., et al. Cephaloceles and related malformastion. AJNR. 1992; 13: 655-690. 